\title{
Testimony
}

by

J. William Currie, Ph.D.

Manager, Energy Systems Modernization Office Battelle, Pacific Northwest Laboratories

$$
\text { before }
$$

The Senate Committee on Governmental Affairs Washington, DC

18 February 1992 
by

\title{
J. William Currie, Ph.D. Manager, Energy Systems Modernization Office Battelle, Pacific Northwest Laboratories
}

\author{
before \\ The Senate Committee on Governmental Affairs \\ Washington, DC \\ 18 February 1992
}

\begin{abstract}
Summary
Good Morning. My name is Bill Currie and I am from Battelle, Pacific Northwest Laboratories.

It is a pleasure to have tie opportunity to talk with this distinguished committee about energy conservation technologies and policies, especially as they relate to federal energy use and the commercialization of energy-efficient technologies. Clearly, using energy more efficiently offers the potential for tremendous cost savings and environmental benefits in the United States and throughout the rest of the world. The challenge, especially with regard to the federal sector, is to lay the foundation for ensuring that the citizens of our nation realize the maximum savings and environmental benefit over the long run. This is the primary focus of my comments today.
\end{abstract}

My organization, Battelle, has been involved in research and development in energy conservation for many years at the Columbus Laboratory and at the Pacific Northwest Laboratory (PNL), which Battelle has operated since 1965 for the Department of Energy. Pacific Northwest Laboratory has several major research programs supporting the DOE Assistant Secretary of Conservation and Renewable Energy, including programs for the Bonneville Power Administration. One of these research programs is focused specifically on improving energy efficiency within the federal sector. This is the Energy Systems Modernization Program for which I am responsible. Our mission is to support DOE's Federal Energy Management Program (FEMP). Through FEMP, over the past 3 years, we have worked with more than twenty federal organizations to identify and characterize energy-efficiency opportunities and to assist the organizations in working with utilities and other third parties to acquire the most life-cycle cost-effective energy technologies. Our activities have included evaluations (completed and ongoing) at over 50 federal installations comprising more than 50,000 buildings and many hundreds of industrial facilities and energy generation and distrioution systems. Our evaluations of these facilities have ranged from cursory to comprehensive. I am confident that the available savings from implementing the most life-cycle cost-effective actions at these installations averages at least $40 \%$ of the annual energy bill.

It is this experience base that I want to draw upon in discussing policies and approaches that would be most effective in promoting the use of energy conservation technologies in the federal sector. 
I want to first summarize my testimony and then show you the technologies that I brought with me today. As I mentioned, the majority of my comments are directed toward federal energy management and use. We were asked to comment on the federal government's potential for "driving the market" for energy conservation technologies, federal management practices that promote or discourage energy efficiency, and the potential for demonstrating new and emerging conservation technologies in federal buildings.

Civen the low discount rate used by the government and mandatory life-cycle costing ${ }^{\mathrm{a}}$ (10 CFR Part 436), the federal government should be leading the private sector in the adoption of new, energy-efficient technologies. Sadly, the opposite is true. Not only is the federal sector lagging the private sector in adopting new energy technologies, but we have seen situations where the federal sector is a decade or more behind.

In the enclosed testimony, I discuss several changes that need to occur for the federal sector to make rapid movement toward energy efficiency. I stress rapid because the cost of waiting is extremely high. From experience with many federal buildings and facilities, we estimate that over $\$ 2$ billion in annual net savings would accrue to the taxpayers from installing all life-cycle cost-effective technologies in federal buildings and facilities. While this represents the savings, $\$ 2$ billion is also the annual cost of waiting. Furthermore, with every increase in energy price, and with every improvement in energy-efficient technologies, the cost of waiting increases.

Simply stated, the government needs to be able to identify and select the most life-cycle costeffective technologies for its 500,000 buildings and facilities, to acquire the funds necessary to do the job, to rapidly implement the procurement process, and to demonstrate that the savings are achievable. It is these four things-money for modernization, technology identification and selection, an improved procurement process, and 'proof of concept'-that must exist in concert for the country to fully realize the savings potential.

- Money for Federal Energy-System Modernization-We estimate that an immediate investment of $\$ 5$ to $\$ 10$ billion for energy-efficient technologies in federal buildings and facilities can be justified using our recommended approach to technology selection. Cost-sharing with utilities and other third parties can halve the federal government's share. However, there is no avoiding the issue that a lot of money is needed to put federal energy efficiency on the road to recovery.

- Technology Identification and Selection-The process that the government uses to identify and select the technologies needs to be well defined and institutionalized. This is important because half or more of the savings potential can be lost forever if agencies do not explicitly consider the full range of cost-saving options, including fuel switching, or if they do not follow the life-cycle costing concept. We believe that a fuel-neutral and technology-independent approach that includes the life-cycle cost concept is the best way to proceed. It is extremely easy to walk through federal facilities and identify energy savings potential; however, it is not easy to identify and plan implementation of all the cost-effective energy savings in terms of fuel and technology type, size of project,

"Life-cycle cost is the net present value of the all the costs of purchasing, installing, operating, maintaining, and disposing of a technology. 
and the scheduling and sequencing of projects to maximize savings. The development of a fuel-neutral, technology-independent approach, coupled with the application and transfer of the approach throughout the federal sector, is necessary to ensure that the maxirnum savings are achieved. Without this approach, we estimate that less than half the savings potential will be captured resulting in an annual loss of roughly $\$ 1$ billion in savings.

- Design and Implement a Process for Rapid Procurement-From our experience, we are convinced that improving the efficiency of existing procurement processes will be a long, uphill struggle. The manner in which changes occur will not be across the whole federal system at one time. Change will occur within an agency at the lowest level of procurement and contracting authority. This is because different operating arms of the same agency have different interpretations of what are considered appropriate procurement and contracting procedures. We recommend that the government design and test different approaches that are likely to lead to totally new procurement and contracting procedures. For instance, since much of the capital necessary for federal energy-system modernization may be found in utility demand-side management (DSM) programs, we believe that tremendous gains can be achieved by explicitly authorizing installations to contract directly via sole source with their utilities for customized DSM programs that support energy-system modernization.

- Implement Model Energy Installation Program-The above three elements need to be combined in a demonstration of a model program at a major federal installation as 'proof of concept' that the projected savings can be realized when the necessary funds are made available, and the most life-cycle-cost-effective technologies are identified, procured, installed, and properly maintained. The U.S. Army Corps of Engineers Construction Engineering Research Laboratory [USACERL] is planning such a program at Fort Hood, Texas. DoD has roughly 200 installations that are, in reality, small unmetered cities. DoD is also the largest energy consumer within the federal government. The "model installation program" should set the standard for all DoD installations in energy efficiency.

We are making progress on several fronts despite the impediments that exist. I will discuss a model approach to working with utilities and provide some examples, including a discussion of the FEMP model program being developed at Fort Lewis in Washington State. I will also provide an overview of a program being implemented to test new technologies in the federal sector and describe the Cooperative Research and Development Agreement (CRADA) process we are using. Finally, I will describe two technologies: one that Pacific Northwest Laboratory has commercialized, and one that we will be commercializing within the next two to three years.

\section{Federal Energy Management}

It is common knowledge that the federal government is the single largest user of energy in the country, consuming nearly 1.5 quads annually at a cost of about $\$ 10$ billion. A third of this energy is used in buildings and facilities, costing us nearly $\$ 5$ billicn-about half of the annua! federal sector bill. Our experience at over 50 federal installations indicates that the energy and dollar savings potential within the federal sector is enormous-currently in the range of 40) 
percent using the most cost-effective commercially available technologies. This is consistent with the findings of recent studies conducted by The Alliance to Save Energy ${ }^{1}$ and the Office of Technology Assessment. ${ }^{2}$ Because both energy prices and efficiencies of end-use technologies will increase over time, the cost-effective energy and dollar savings potential within the federal sector will easily exceed 50 percent of the annual federal sector energy bill by the year 2000 , assuming business as usual.

On April 17, 1991, the President issued Executive Order 12759 relating to federal energy management. Among its several goals are directives to increase energy efficiency in buildings and industrial facilities by at least 20 percent by fiscal year 2000 compared to 1985 levels. If the federal installations we have visited and evaluated are representative (and we believe that they are), then it should, on average, be very easy to identify projects which, if implemented, would achieve the 20 percent goal by the year 2000 .

However, I believe that reaching the goals is not the important issue. It is how we reach the goals that really matters. Executive Order 12759 directs federal agencies to pursue the goals by procuring the most life-cycle-cost-effective technologies. In short, E.O. 12759 mandates the criterion for choosing the technologies to meet the goals. I cannot overemphasize the importance of compliance with the life-cycle costing concept. Effectively implementing the life-cycle costing approach will ensure that the majority of the energy cost-savings potential in federal facilities will be captured through the procurement and installation of the most cost-effective, energy-efficient technologies.

\section{Importance of Life-Cycle Costing in Procuring Technologies}

How we reach the goals is important because the nation can save a lot of money by installing the most cost-effective technologies. In fact, following the life-cycle costing principle is a necessary step to capture the full 50 percent of savings potential by the year 2000. If the government does not implement life-cycle costing on a wholesale basis, then a likely outcome will be to approach the 20 percent goal, but in the process, the government will lose most of the remaining 30 percent of savings potential.

A good example is in the retrofit of lighting systems. There are many different lighting systems that would save energy and dollars if installed in your office building. Under the life-cycle cost concept, you should seek ever more efficient lighting technologies until the last dollar you invest in the technology saves just one additional dollar of life-cycle cost. You could install a lower first-cost lighting system that saves money and energy when compared to your existing system, but the government would still be paying more for electricity than it would cost to save it. Furthermore, for the foreseeable future, the opportunity to go back into the building and capture these additional savings is lost because it may not pay to throw away the new lower cost lighting system the government has just installed. This behavior-installing a system that is more efficient than the existing system but falling far short of the most cost-effective system-is called "cream skimming." Rampant cream skimming wan significantly reduce the dollar savings realized from retrofit, and the rate at which new energy-efficient technologies are procured by the federal government. And, because the sales of new energy-efficient technologies are reduced, the number of jobs that can be created and maintained in the process of saving federal dollars will be reduced. 
Based on our experience with FEMP and other federal agencies, we have developed a rule-ofthumb. In general, we have found that it is life-cycle-cost-effective for a government facility to invest from one to two times its annual energy bill in energy-efficient technology. The total federal energy cost for buildings and facilities is about $\$ 5$ billion each year. Extending the ruleof-thumb to the entire federal sector would suggest that a level of investment of $\$ 5$ to $\$ 10$ billion between now and the year 2000 would be warranted, and this investment would save over $\$ 2$ billion annually. Furthermore, we estimate that a net present value of savings in excess of $\$ 35$ billion would result from this "deficit reduction investment."

In addition to the savings that will be realized, procuring the most life-cycle cost-effective energy technologies is one of the best ways for the federal government to drive the market for new, highly efficient technologies. The primary reason for this is the low discount rate used by the government relative to the private sector. The lower rate will generally result in the selection of new, highly efficient technologies as the most life-cycle cost-effective. A similar analysis for the private sector generally results in less efficient levels of technology being the most cost-effective.

Use of the life-cycle cost concept also pays other dividends because more energy projects qualify as having positive net benefits as opposed to basing procurement decisions on first cost or simple payback. Implementing the most life-cycle cost-effective projects will result in more savings, a higher level of investment, more energy-efficient technologies sold, and more jobs in industries and firms that produce and/or install the technologies. The job-related benefits can be extremely widespread, benefiting a broad array of companies and trades. And the potential exists in every single state.

I have painted a rosy picture of the win-win potential in achieving energy efficiency in federal buildings and facilities: over $\$ 2$ billion in annual savings to the taxpayers, reduced environmental pollution, ability to drive the adoption of highly efficient life-cycle cost-effective technologies, and job benefits accruing to industries and individuals throughout every state. Given this potential for such huge benefits, spread across so many citizens, two obvious questions arise:

\section{What are we doing to take advantage of this opportunity?}

What else needs to be done?

\section{Rapid Deployment Requirement}

There are five elements of a comprehensive program that is needed to rapidly exploit the energy-efficiency "profits" available to the federal government. We must:

Realize that energy-efficiency potential is an ASSET and treat it as such. Because we have neglected our energy-system physical infrastructure, the government is now controlling a huge asset in the form of energy savings potential. Today, it is both difficult and expensive to build electrical generating capacity. The government's asset in energy savings potential can help solve this problem. This may seem perverse; however, this is exactly the situation we are in. This federal asset can be gathered, packaged, and sold, 
producing both tremendous financial returns and environmental benefits. Furthermore, this is an extremely costly asset to hold-the annual cost of holding this asset equals the cost savings from liquidating the asset-roughly $\$ 2$ billion per year for existing federal buildings and facilities. And this cost increases with every energy price increase and with every improvement in the efficiency of energy technologies. Federal trustees, from the President and Congress on down, need to understand that energy-efficiency potential is an asset. And indeed, both the Congress and the President have implicitly acknowledged this through legislation addressing shared energy savings and utility demand-side management programs, and with the issuance of E.O. 12759.

- Understand the characteristics and attributes of our energy-efficiency asset so we are prepared to market it. We need to understand the size, quality, value, and unique characteristics of our energy-efficiency asset. For example, we need to have reasonable estimates of the amount of potential savings in our lighting systems, the ease of replacing these systems, the geographical dispersion, the types of technologies needed, how implementation should proceed, and (after the retrofit) how to ensure that the savings really do materialize and persist. I will provide some insight to these questions later.

- Understand the market for selling the asset so we can negotiate the best price. Taxpayers have historically purchased energy efficiency from federal agencies by providing funds for replacing portions of the federal energy-system infrastructure. Today, federal agencies have legislated authorities that allow them to access additional sources of capital through Shared Energy Savings (SES) programs and utility demandside management (DSM) programs. The most important opportunity available to agencies is the availability of utility DSM programs. These programs are changing rapidly and with significant variation across both electric and gas utilities. Outside of traditional government funding mechanisms, utilities represent the most important market for the federal government to sell its energy-efficiency resource. Utilities can finance and cost-share energy-efficiency programs with the federal government and they have the potential to provide low cost capital. The lower the cost of capital, the lower the total cost of new technology, resulting in more new, highly efficient technologies being procured and installed. The government has the lowest cost of capital available. The utilities have the lowest cost of private sector capital available to the federal sector. Combining federal dollars and utility dollars will generate significant savings for the nation's taxpayers. The least attractive approach is to utilize private sector capital from other than utilities, because the required rates of return are significantly higher. In our opinion, only if no other options exist, should this latter approach be pursued. I have several examples of innovative programs that federal agencies are cost-sharing with utilities which I will discuss later in this testimony.

Understand the barriers to rapid deployment and federal acquisition of energy-efficient technologies and design and test new approaches through a "rapid deployment test program." Even if unlimited capital were available, and if all the life-cycle cost-effective technologies could be identified, the federal government could not move rapidly to modernize its energy systems. We know that the governn.unt is several years behind the private sector in purchase and use of many technologies. Congress needs to consider 
bold steps to test new approaches to procurement. We have several thoughts on this. One idea would be to implement a "rapid deployment test program" at a government installation with the goal of identifying, installing, and verifying the performance of all the energy technologies that are life-cycle cost-effective and to do this as rapidly as possible. A reasonable set of objectives would be to minimize the federal cost of procuring the technologies by leveraging contributions from a utility. The federal organization charged with the responsibility to design and conduct the test should be required to comply with the spirit of existing procurement and contracting regulations but, for the test, should be exempt from adhering to any existing procedures for implementing federal contracting and procurement regulations. The rapid deployment test program could serve as a test bed utilizing the Cooperative Research and Development Agreement (CRADA) concept. The success of the test could be measured against an independent assessment of the technologies, labor, services, etc., that would have likely been procured through traditional means. This, or a similar approach, could very well lead the government to adopt a totally new approach for rapidly moving energy-efficient technologies into the federal sector.

Realize that incentives are very important from the bottom to the top. Our experience indicates that there are many good people in the government who want to make some. thing happen; to do the right thing. Even so, there are not enough of these people. Enhanced recognition through a variety of means is crucial to creating an attractive energy management career path. There are several mechanisms, some of which are being implemented, that make sense. These include enhanced cash awards, additional paid annual leave, agency and installation retention of energy dollar savings, and the authority to hire additional energy-efficiency personnel at the agency and installation level.

\section{What is Being Done}

I want to discuss some of our recent experiences and relate these to the issues that I raised abcve, especially the issues related to understanding the characteristics of our energy-efficiency asset and marketing this asset to utilities. You may be aware of the concept of integrated resource planning (also called least-cost planning) being implemented by utilities. The concept is for a utility to identify and evaluate all the potential energy resources available to serve its customers. For an electrical utility, the integrated resource plan (IRP) includes a schedule of all potential electrical generation, potential electricity purchases, and all electric energy-efficiency resources (savings) that could be acquired by the utility. Maximum benefit to ratepayers can be achieved by the utility systematically acquiring the minimum cost bundle of electrical resources to meet its growth needs. Today, the lowest cost resources are almost always energy-efficiency resources such as lighting, insulation, etc.

As part of our support to FEMP, Pacific Northwest Laboratory is designing and implementing an approach for integrated resource planning and acquisition specifically tailored for the federal sector. ${ }^{3}$ The approach is applicable at both the agency and installation level. Embodied in the approach is the concept of life-cycle cost-effectiveness. The approach is fuel-neutral and technology-independent. The goal is to provide reliable energy services at the lowest possible cost. 
We have begun to implement the IRP approach and at the same time, offer workshops to federal energy managers on how they can use this approach to identify and acquire the most life-cycle cost-effective energy resources. In implementing the approach, our goal is to encourage federal agencies and installations to attempt to acquire all the cost-effective technologies that are identified. In working at federal sites, we have found that lighting is almost always the single most important electrical end-use for us to concentrate upon. There are two reasons for this. Lighting invariably offers the greatest potential for dollar and energy savings, especially when coupled with cost sharing from a utility DSM program. However, the savings potential from replacing lighting systems is very important for another reason. Lighting provides the "hook" that can make it worthwhile for the agency or installation, the energy services company, and/or the utility to commit to identifying and implementing all cost-effective projects at an installation or in a building.

FEMP has recognized this by initiating the Federal Relighting Initiative (FRI). In our support to FRI, we have produced estimates of the number of existing lighting fixtures in federal buildings (over 60 million) and will soon produce estimates of the potential for replacing them. The federal demand for new lighting technology is, of course, driven by the rate at which the government chooses to replace the lighting fixtures. Understanding the characteristics of the government lighting systems is only one piece of the whole puzzle. Our recommendation is to not stop with lighting because lighting is but one of several interactive energy systems within a building. If the government is going to incur the costs of organizing a major lighting retrofit program at an installation or a building, ideally, all cost-effective energy-efficiency measures should be identified and implemented at the same time. We have found that significant energyefficiency potential exists in motors, transformers, chillers, water heaters, heating, ventilating, and air conditioning systems, and steam and high-temperature hot-water systems at most federal installations.

At Pacific Northwest Laboratory, we are working in concert with FEMP, other federal agencies, other national laboratories, and private contractors to implement our integrated resource planning approach at federal installations. We are providing the technical and analytical paradigms and the program management to put large "cradle to grave" energy-efficiency programs in place. One way in which this is being accomplished is through the Infrastructure Modernization Implementation Council (IMIC), an organization comprising representatives of nine DOE laboratories and six DOE field offices currently chaired by PNL. IMIC was established through FEMP to ensure that the specialized expertise within the laboratories was immediately accessible to assist other federal agencies in energy systems modernization activities. Through IMIC, we have been able to acquire expertise from other laboratories in support of our activities and we are in the process of securing additional agreements.

Another mechanism that is being used is the Mobile Energy Laboratory [MEL] Use Committee comprising representatives from DOE, Army, Navy, and Air Force. This committee, which we chair, has the responsibility of managing and mairtaining an inventory of energy end-use monitoring and test equipment and for establishing energy test procedures. Through the MEL Use Committee, we have established working relationships with the DoD laboratories ${ }^{4}$ and are currently collaborating on several programs. For example, we are working with the Army Corps of Engineers at several Army installations and are supporting the Construction Engineer- 
ing Research Laboratory [USACERL] and the Huntsville Division in the design and development of a "model installation" energy program at Fort Hood.

We are also working with several utilities to design prototype DSM programs to serve as models across the federal sector and with other utilities. While utilities have had DSM programs in place for years, we found that they are designed for the private sector customer and that it is not easy for the federal customer to participate. The two major barriers are that (1) the customer must spend operating or capital funds up-front and (2) the customer must assume responsibility for procuring all of the services and technologies for the retrofits. We have designed an approach that would allow the federal customer access to the lowest cost capital available. The cost of capital, more than any other variable, influences the amount and efficiency of new technologies which qualify as the most life-cycle cost-effective. The lower the cost of capital, the more new, efficient technologies qualify. In our approach, the federal installation also avoids a major procurement hurdle by having utilities competitively procure energy services and technologies, making these available through a sole source procurement between the federal installation and the utility.

In summary, in the model DSM approach we designed with FEMP and other federal agencies, we are asking the utilities to contract directly with the federal installation, agreeing to:

- provide 100 percent of the up-front financing,

- fund a significant portion of the installed cost of the technologies, and

- contract with the Energy Service Companies (ESCOs) to implement the energy system modernization program on the federal installation.

Having an understanding of the value of the energy-efticiency potential at the installation puts the federal customer in the best possible position to negotiate its share of the cost of installing the technologies. Our recommendation to the federal installations is that the utility can typically afford to pay more than 50 percent of the total installed cost. The federal installation's portion of the cost sharing can be repaid by either an adjustment on its utility bill, or by direct cash payments from savings in energy costs.

As I mentioned above, we are currently working with several utilities to implement this type of program. The three utilities with which our program is the furthest along are Tacoma Public Utilities, Georgia Power, and Niagara Mohawk. Federal organizations currently involved in the model program are the Army, Air Force, and DOE. I have a description provided by Georgia Power of its Department of Defense Energy Partnership (DEPP) program and a recruiting announcement produced by Tacoma Public Utilities (TPU) as this utility is attempting to hire four full-time people just to manage and support the model program being implemented at Fort Lewis.

I want to describe the Fort Lewis program to you because it is the furthest along and has characteristics of what we envision happening at other installations.

Fort Lewis is an installation within the Army Forces Command (FORSCOM), located at Tacoma, Washington. It is typical of large government installations in many ways. ${ }^{5,6}$ It is 
relatively large with a permanent population of about 25,000 and a daytime population of 35,000 . The annual energy bill is $\$ 12$ million with electricity representing about 35 percent of the total. The Fort has 4,500 buildings and the only electrical meters are at three substations serving the Fort. Fort Lewis is really a small city comprising residences, commercial buildings, warehouses, schools-in many ways a troop base is a typical American town.

The staff at Fort Lewis and FORSCOM are dedicated and committed and have made many energy-efficiency improvements over recent years. Likewise, the energy conservation program staff at TPU have a reputation for innovation. TPU has no excess capacity in its generation system and needs to build more generating plants, purchase more electricity, or acquire electric energy savings from its customers.

Fort Lewis is an ideal opportunity for TPU. Both the utility and the Fort quickly realized that if the Fort could provide an assessment of the potential savings, and if all the parties could overcome all the bureaucratic red tape associated with a huge "we've never done this before" kind of program, then it could be a real "win-win" for everyone.

The effort has taken uver a year, but all formal agreements are expected to be in place within the next couple r.ionths. TPU is procuring energy services companies on a competitive basis, specifically to serve the Fort. The Fort will contract directly with TPU for the installation of new technologies. TPU will pay for 100 percent of the total cost of purchasing and installing the technologies. The Fort will reimburse TPU 15 percent of this total cost. The program is expected to take between 4 and 6 years to complete and could involve as much as $\$ 10$ million of investment capital. We estimate the net present value of savings to the government will be at least $\$ 15$ million. The majority of the electrical savings are in lights, but other new technologies such as high-efficiency motors and transformers will also be installed.

With the success of the Fort Lewis program, we are now beginning to work with other federal installations within the Bonneville Power Administration service territory. For example, we are now working with the DOE Richland Field Office, the Westinghouse Hanford Company, and the In-House Energy Management [IHEM] organization at DOE headquarters together with Bonneville to begin a similar fuel-neutral and technology-independent assessment at Hanford, including implementation of a model DSM program for DOE installations.

Our goal is to put at least two more model DSM programs in place in 1992. Implementing this model program with the majority of utilities will continue to be a slow process because the approach is a major step for both the government and the utilities. Both sectors have institutional constraints that need to be addressed and overcome. We have found, for example, that no two federal organizations have the same interpretation of procurement and contracting authorities and procedures. Indeed, no two installations within the same federal agency will interpret these procedures the same way. The utilities also have issues to resolve. They need to be able to convince their non-federal ratepayers and their regulatory commissions that investing in the federal sector is necessary to achieve the savings, that this approach is fair and equitable, and that ratepayers will benefit through lower energy bills over time.

This is one of the reasons why we suggested consideration for the rapid deployment test program discussed above. Again, the idea would be to start from scratch with a committed installa- 
tion and utility and to rapidly characterize the energy-efficiency potential, procure, install, and verify the performance of the most cost-effective energy technologies within a fuel-neutral and technology-independent framework. Many opportunities exist, for example, in fuel switching from petroleum products to natural gas. This, in fact, is the greatest single cost-saving action that could be taken at Fort Lewis. Unfortunately, there is no existing "deep pocket" to pay for nonelectric technology change at the Fort. The net present value of savings fr $r$ monelectric energy efficiency at Fort Lewis approaches $\$ 50$ million. Combined with the savings potential from electric energy-efficiency retrofits, the total net present value of savings potential at Fort Lewis exceeds $\$ 65$ million!

Within the rapid deployment test program, the government could purchase, test, and verify technologies that have not yet penetrated the federal sector. The government would need to target funds specifically for this activity. We have found that it is difficult to convince an agency or installation to be the first buyer of new technologies. And the reasons are understandable. The energy manager's job is to keep equipment running to ensure that the installation can support its mission. The last thing in the world that the energy manager needs is an "experiment" that the installation is asked to pay for and that it is stuck with if the technology does not perform.

Through FEMP, we have a sriall test bed program for putting in place technologies that are in the early commercialization stages. In 1991 we issued solicitations for utilities and vendors to enter into Cooperative Research and Development Agreements (CRADAs) to install and verify a new gas chiller and a new gas-engine-driven roof-top HVAC system. We received an excellent response from both industry and utilities who have offered to make equipment and funds available to work with FEMP and the Pacific Northwest Laboratory on verifying the performance and life-cycle costs of these technologies. We plan to place at least one award this year. Also, we plan to design and issue solicitations for additional technologies during 1992. The use of CRADAs to test and verify new technologies would fit nicely into the rapid deployment test program.

\section{Technologies Commercialized}

We were asked to describe what we have done to commercialize technologies that contribute to energy conservation. I want to describe one example of a survey meter/recording technology that won a Federal Laboratory Consortium Award (FLC) for our staff at Pacific Northwest Laboratory. No more than 30 of these awards are granted in any one year. Every laboratory throughout the federal system is eligible. Pacific Northwest Laboratory has received the FLC award 16 times, more than any federal laboratory. Needless to say, we pride ourselves on being at the forefront of rapid deployment of technology.

The technology I want to describe is referred to as a $\mathrm{C} 180$ data logger. We have licensed this technology to Synergistic Control Systems in New Orleans. This was a very important piece of technology to Synergistic as attested to by the firm's president, A. J. Finnin, who has publicly stated that "were it not for Pacific Northwest Laboratory's technology transfer of the technical know-how which resulted in the C180 Survey Meter/Recorder and associated software, Synergistic Control Systems would not be in business today." 
The C180 allows utilities and federal energy managers to quickly identify how energy is being used within buildings and, also, at large, unmetered installations. ${ }^{4}$ The unique aspect of the $\mathrm{C} 180$ is the ability to monitor up to 16 channels of energy data at one time, including end-uses such as refrigeration and air conditioning. Each channel can record voltage, current, apparent power, and true power. The $\mathrm{C} 180$ also has additional channels for monitoring temperature, wind speed, steam flow, and a variety of other variables. Multiple C180s can be connected in clusters of up to 100 units with a single communication port.

Data collected by the $\mathrm{C} 180$ is stored in a microprocessor and through a built-in modem can be transferred via telephone lines to a central computer anywhere in the world. We have found that remotely collecting energy use data in this fashion is the most cost-effective approach available.

The nriginal concept of the $\mathrm{C} 180$ evolved from a small allocation of discretionary research and development funds under the control of Pacific Northwest Laboratory's Director of Research. A prototype was developed under sponsorship by the DOE Office of Building Technologies and subsequently field tested on a large scale as part of Pacific Northwest Laboratory's End-Use Load and Conservation Assessment Program (ELCAP) funded through the Bonneville Power Administration. The $\mathrm{C} 180$ is now a critically important technology in our efforts to assist FEMP in improving energy efficiency within the federal sector.

To show you the kind of information that can be produced from data collected by the C180, I have a handout for each of you showing the energy end-use breakdown at DOE's headquarters, the Forrestal Building. We collected this data to assist DOE in determining the potential for a shared energy savings project in lighting. You can see that lighting contributes to about onethird of the electrical load at Forrestal. From the data we collected with the C180, and our subsequent analysis, DOE concluded that it would pay to implement a shared energy savings lighting project and is in the process of doing this.

\section{Technologies Under Development}

I would also like to briefly describe one technology that researchers at our Columbus, Ohio, laboratory are developing that we believe has tremendous potential for contributing to improving the nation's energy efficiency in an environmentally-safe manner. This technology is the Battelle aerogel, which derives from a general class of materials called aerogels. Aerogels are light-weight materials with widespread potential for thermal insulation. Escalating energy costs, the phase-out of CFC-derived polyurethane foams by the year 2000 , and the required 25 percent increase in energy efficiency of appliances by 1993 are primary drivers for developing this environmentally-safe, highly-efficient Battelle material.

Aerogels consist of an inorganic oxide (typically silica) and air. They were first produced in the 1930s; however, the materials were not widely used because of their fragile nature. The aerogel's fragility is a function of how it has been made. Traditionally, aerogels are prepared by subjecting a sol-gel material to supercritical drying. During the drying process, the liquid in the sol-gel is removed without collapsing the structure. The resulting material has high porosity, extremely low density, and high surface area. The result is a material with very small pore sices, exhibiting excellent thermal insulation and sound absorption properties. 
The aerogel samples that I have for you today are the conventional aerogels which, as I have indicated, are very fragile. The challenge for Battelle researchers at Columbus has been to find an effective and economical way to enhance the strength of aerogels without sacrificing their insulating qualities. If this could be accomplished, the material would find immediate application wherever insulation is needed.

Battelle researchers have developed a process to develop aerogels that are up to 50 times stronger than conventional aerogels and that can be produced in less than one percent of the time it takes to produce a conventional aerogel. This improved material can be compressed and molded without breaking, is not damaged (as conventional aerogels are) by exposure to water, and has at least as good insulating properties as conventional aerogels.

We are very excited about the potential of the Battelle aerogels. One proprietary aerogel patent is pending. Our development schedule indicates that within five years, Battelle aerogels will be commercially available.

\section{Recommendations}

There is tremendous potential for saving money, reducing the deficit, improving the environment, increasing the sales of energy technologies, and creating jobs through immediate and aggressive attention to energy efficiency within the federal sector. The key ingredients are:

1. Availability of government funds for cost-sharing large-scale energy efficiency programs with utilities.

2. A fuel-neutral, technology-independent approach, patterned after the integrated resource planning process used by utilities, but incorporating the concept of lifecycle costing, to ensure that the most cost-effective technologies are procured.

3. Expediting the procurement process with explicit new authorities such as allowing agencies to sole source all energy services from their utility.

4. A model energy installation program that can demonstrate the value of the proposed approach.

The most important of these ingredients is the availability of federal funds. The old adage, "you can't make money without spending money," really strikes at the heart of this problem. On the issue of energy efficiency in the federal sector, it will take substantial federal investment to save substantial energy dollars.

\section{References}

1. M. Hopkins. 1991. Energy Use in Federal Facilities: Squandering Taxpayer Dollars and Needlessly Polluting Our Environment. The Alliance To Save Energy, Washington, D.C. 
2. U.S. Congress, Office of Technology Assessment. 1991. Energy Efficiency in the Federal Government: Government by Good Example? OTA-E-492, U.S. Government Printing Office, Washington, D.C.

3. J. W. Currie, R. W. Reilly, R. W. Brancato, and J. A. Dirks. 1991. "Modernizing Federal Energy Systems: The FEDS Development Approach." Energy Engineering 88(4):6-19.

4. G. B. Parker and J. L. Heller. 1991. "Measuring Energy Efficiency Improvements with the Mobile Energy Laboratories." Energy Engineering 88(4):36-49.

5. T. J. Secrest, J. W. Currie, J. G. DeSteese, J. A. Dirks, T. J. Marseille, G. B. Parker, E. E. Richman, and S. A. Shankle. 1991. Fort Lewis Electric Energy Baseline and Efficiency Resource Assessment: Executive Summary. PNL-7763 Ex Sum, Pacific Northwest Laboratory, Richland, Washington.

6. J. Fey and D. Moore. 1990. "Energy Efficiency Project at Fort Lewis, Washington: Basic Training in Patience and Persistence." Presented at the American xublic Power Association Consumer Services Session, Colorado, Springs, Colorado, November 4-6, 1990. 


\section{VITA \\ J. William Currie, Ph.D. \\ Manager, Energy Systems Modernization Office \\ Infrastructure Modernization Program \\ Battelle, Pacific Northwest Laboratories}

\section{EDUCATION}

B.S., Mechanical Engineering, University of Maine, 1964

M.S., Resource Geography, Oregon State University, 1971

Ph.D., Civil Engineering and Natural Resource Economics, Oregon State University, 1975

\section{EXPERIENCE}

As Manager of ESMO, Dr. Currie's responsibility is to support the mission of DOE's Federal Energy Management Program, which is to provide leadership in moving the federal government toward energy efficiency. In this capacity, ESMO provides assistance to many organizations including DOE, DoD (Army, Air Force, Navy, USMC), GSA, DoT, BPA, HUD, USDA, and the Conservation Law Foundation of New England. ESMO assists these agencies on a broad array of energy programs with the primary focus on developing and implementing integrated resource plans. The approach designed by Dr. Currie and his staff is fuel-neutral and produces a schedule of the least cost resource options for an installation or agency. A cornerstone of the ESMO approach is a model demand-side management (DSM) program for utilities to offer to their federal customers. ESMO is currently working with Georgia Power, Niagara Mohawk, Pacific Gas \& Electric, Potomac Electric Power, Tacoma Public Utilities, and Florida Power \& Light to implement the model DSM program.

During his career at PNL, Dr. Currie has developed and directed several multi-disciplinary programs to estimate the need for, and benefits from, advanced en-rgy and environmental control technologies and has provided expert testimony on the results of his research. He has recently managed a program to assess the potential for high-temperature superconducting transformers to contribute to the nation's electric power, transmission, and distribution system. Dr. Currie has directed research on the consequences of nuclear reactor accidents, global climate change, and acid deposition. He has also designed and directed several feasibility analyses of energy and regional development projects related to public and private sector investments.

Prior to joining PNL, Dr. Currie spent two years as a private consuitant working on water resource and market assessment issues for domestic and international clients. He spent three years as a mechanical engineer with the Smithsonian Astrophysical Observatory in Maui, Hawaii. He has also been employed as a design engineer by Georgia Pacific Corporation.

Dr. Currie is a member of several professional organizations, has served as a reviewer for several journals, is listed in Who's Who in the West, and is the author of over 50 published research reports and papers. 

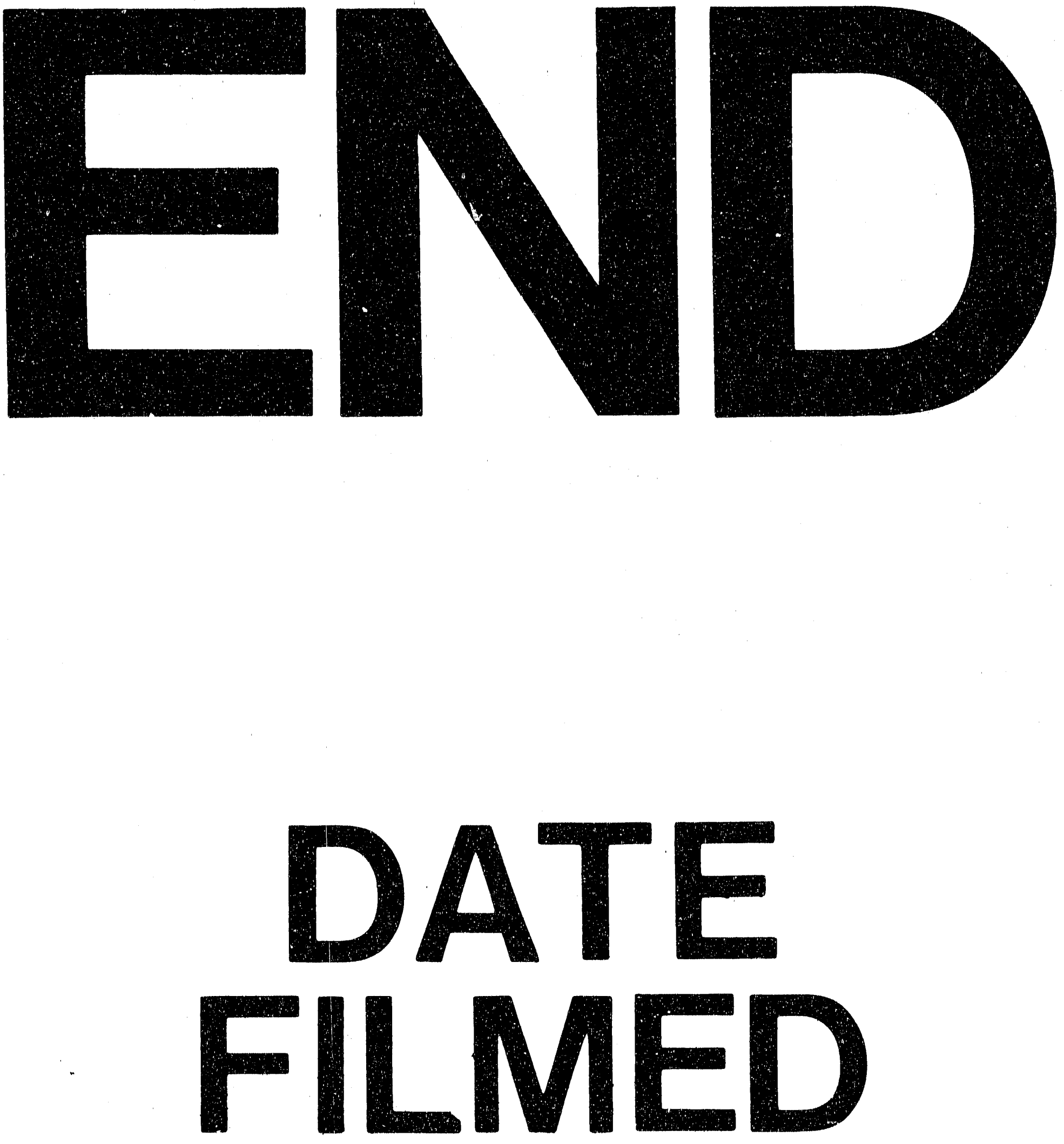

$=$

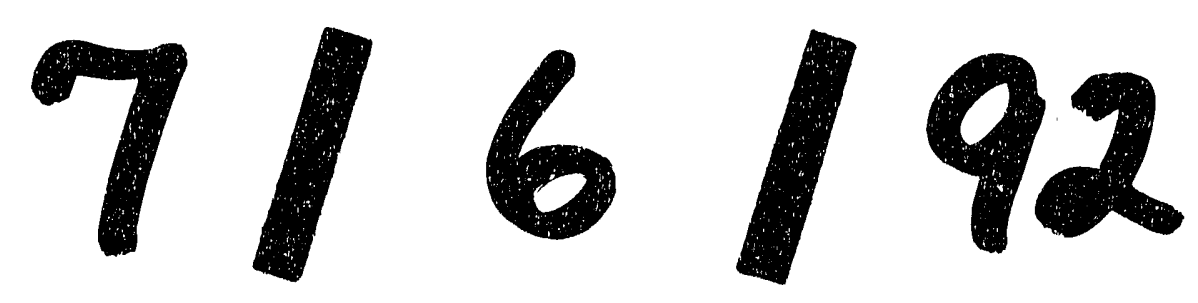


